\title{
Artelogie
}

Recherche sur les arts, le patrimoine et la littérature de l'Amérique latine

17 | 2021

Transformaciones en Cuba contemporánea: cultura y sociedad

\section{¿Musicología mundial en chancleta de palo? Entrevista a Danilo Orozco}

\section{Miviam Ruiz Pérez}

\section{(2) OpenEdition}

\section{Journals}

Edición electrónica

URL: https://journals.openedition.org/artelogie/9928

DOI: 10.4000/artelogie.9928

ISSN: 2115-6395

Editor

Association ESCAL

Referencia electrónica

Miviam Ruiz Pérez, «¿Musicología mundial en chancleta de palo? Entrevista a Danilo Orozco»,

Artelogie [En línea], 17 | 2021, Publicado el , consultado el 15 septiembre 2022. URL: http://

journals.openedition.org/artelogie/9928 ; DOI: https://doi.org/10.4000/artelogie.9928

Este documento fue generado automáticamente el 15 septiembre 2022

All rights reserved 


\title{
¿Musicología mundial en chancleta de palo? Entrevista a Danilo Orozco
}

\author{
Miviam Ruiz Pérez
}

\author{
"Los artistas no piden limosna, piden justicia" \\ Extraído del libro Pedimos la palabra \\ Fundación SGAE, 2017
}

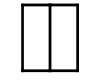

1 Todo encuentro con el musicólogo Danilo Orozco (Santiago de Cuba, 1944) corre el peligro de convertirse en un interminable diálogo, no sólo con la historia de la música y la musicología, sino con una corriente de pensamiento que se mueve entre interrogantes de muy diversa índole. Por una parte, su extensa e intensa carrera (experiencia docente abierta de treintaiséis años), colaborador de prestigiosas universidades e instituciones de todo el mundo como Smithsonian Institute de Washington, Universidad de California (Tribunal a distancia), Universidad Salamanca, Fundación Sojo de Caracas, Conservatorio TChaikovsky de Moscú, Universidad de Chile, Universidad de Austin (LAMR), la BBC de Londres y el Who's who in Music. Por otra, su categoría de doctor Summa Cum Laude en Ciencias Musicológicas y Filosóficas por la Universidad "Humbolt" de Berlín, Profesor e Investigador Titular en Cuba; además sus trabajo teórico-prácticos en problemáticas medulares de la historia y el análisis musical, sus casi "incapturable" cuatro libros, e innumerables ensayos, toto eso matizado por su admirable y multifacético desbordamiento, el carácter polémico y controversial de sus planteamientos, los "entramados" conceptuales de una mente en movimiento perpetuo. Para nuestra suerte, lo inmensurable de Orozco es atrapado por su fuerte raigambre oriental que convierte el discurso en un divertido juego donde la filosofía y el cubaneo se dan la mano. De modo que lo más aconsejable ante semejante hoja curricular; es comenzar con los inicios de su formación...

2 Mi formación fue un proceso de autogestión aleatoria y a ratos cuasi caótica (la actual teoría del caos me vendría muy bien). De niño, entre ocho y diez años, me vinculé a la práctica coral de la escuela donde estudiaba. Fui cantor solista bajo la dirección de la profesora Moraima Guasch y me inicié también en el ejercicio de la lectura musical y los 
rudimentos de la teoría elemental, y luego en el estudio de la guitarra clásica con el veterano profesor Doufourneau. Mis actividades músico-artísticas desde entonces abarcaron toda la década del $50 \mathrm{y}$, luego del 59, presentaciones concertantes o acompañantes (con la guitarra) en teatros y salar o dirigiendo coros en el Anfiteatro habanero.

¿Conserva documentos, memoria escrita o algo?

4 Sí, no hay que creérmelo, nada de esto ocurrió en el cafetín de Pocholo, ni en un tocaíto con fulanos o menganos (aunque, claro, hay cafetines y tocaítos gloriosos). ¿Cuántos años serían de vida musical activa?

6 Si nos atenemos a la documentación, aparte de los sesenta que cumplo en edad y de los treintaiséis de trayectoria musicológica, vengo cumpliendo prácticamente cincuenta años no exactamente de una línea músico-escénica mantenida, pero al menos de un temprano quehacer artístico de no poca intensidad por etapas, cual me ocurriera al cabo de los años con el decursar guitarrístico y otra fase de la actividad coral (director y arreglista muy joven).

7 ¿Qué recuerdo conserva de esa época?

8 Mi actividad coral transcurría en el ámbito de la Primera Iglesia Bautista, donde me crié por la tradición de mis padres, marco muy cercano a la vida del héroe Frank País. Pese a que no era de mi generación, sino de la de uno de mis hermanos en la Escuela Normal de Maestros, Frank constituyó un ejemplo de ética, firmeza cívicorevolucionaria y humanismo, amén de que esa un notoriamente intuitivo músicoorganista y coral (aspecto bastante poco estudiado en su vida). Su naturaleza era muy especial, extraordinariamente sensible e impredecible.

¿Qué hay de sus amigos o círculos afines?

10 En la etapa de los tempranos 60 , este quehacer coincidió con la de un grupo informal de cultivadores de la guitarra y la música: médicos, ingenieros, empresarios, promotores y músicos estudiantes (como Eugenio Deschamps, el hoy presbítero y músico Jorge Catasús o yo mismo). En ese ámbito (y paralelo al Conservatorio "Esteban Salas") también germinó la figura del que entonces era un niño -con diez o doce años- y que hoy ha llegado a ser uno de los pilares de la guitarra mundial de nuestros días, Manuel Barruecos. Se inició con el propio Doufourneau y luego continuó bien de lleno con Manolo Puig. Y tiempo después completó su formación en los Estados Unidos.

11 En ese grupo santiaguero se insertaron, además, varias visitas de Leo Brouwer, entonces un joven virtuoso de la guitarra y sólido compositor, con un repertorio que se disfrutaba mucho dentro de aquel grupo. No sólo Leo se impresionó con las potencialidades interpretativas de "Barruequitos", sino que, igualmente, recomendó que Manolo Puig sistematizara su clase en el Conservatorio "Salas" (que devino decisiva para el desarrollo del guitarrismo clásico cubano desde oriente a occidente, es decir, teniendo en cuenta todas las bases sentadas desde Nicola y sus discípulos, entre ellos el propio Brouwer). Es obvio que tenía gran repercusión en todos nosotros cualquier tipo de contacto e intercambio con Leo, Pablo Hernández Balaguer (a distancia) o la actividad de profesores (Edmundo López, Miguel García, Edgardo Martín), en una incipiente Facultad de Música en la Universidad de Oriente, primera de su tipo en el país (hecho que aún hoy se minimiza, cuando no se oculta), también los buenísimos músicos que hicieron la primera audición en vivo de las obras de Esteban Salas en la Catedral, y otras personalidades. Aquel grupo de amigos era una suerte de círculo 
neoflorentino donde el "fervor" significaba entrega músico-artística de quilates. Germinaron proyecciones para la ciudad, el ámbito cubano y la cultura mundial, aunque parezca increíble, toda vez que, además del cruce del aún temprano pero ya resonante Brouwer con el naciente "alumbrado" Barruecos, el ambiente músicoescénico y músico-cultural de la ciudad, los buenos músicos locales, nacionales y extranjeros que pululaban por allí entonces (eco tardío del esplendor santiaguero del XIX), el accionar de los nacientes Orfeón Santiago y Coro Madrigalista, etc., no podían ser inútiles en modo alguno. Lástima que. A tenor de insensibilidades y burocracias culturales, tal esplendor de los 60-70 decayera mucho (lo he vivido en mi carne) hasta el momento actual, sobre todo la muy notable diversidad cultural que antes tuvo Santiago.

A propósito de Leo, ¿qué lo motivó a estudiar su obra?

Cuando todavía yo tocaba algo, me era muy afín su versatilidad, la funcionalidad en el manejo del instrumento, la fuerza comunicativa y madurez pese a su juventud y, con el tiempo, la manera en que iba manejando mínimas estructuras con eficientes resultados expresivos. Más adelante, según sedimentaba mi formación, me atraía la versatilidad de géneros que abordaba, el ingenioso aprovechamiento tímbrico-orquestal, la desacralización de valores en buen número de obras y la manera en que los recursos expresivos estaban en función de un rejuego, gesto y a veces teatralidad interior. Recuerdo todavía cuando me dio personalmente la primera copia de su célebre "La tradición se rompe... pero cuesta trabajo", para análisis con mis alumnos de la ENA y posgrados que dicté en universidades de Latinoamérica.

¿En qué contexto ubicar sus conocidos e importantes estudios de lo popular?

Santiago de Cuba (sus montañas, llanos y zonas aledañas) ha sido simiente de medulares manifestaciones de la base popular profunda y, por supuesto, no sólo en la importante, visible y archiconocida creación trovadoresca, o en los entrecruces de lo trovero y lo sonero (como es el caso canónico de Matamoros o de los Hierrezuelo, o el propio Compay Segundo, y que tienen homólogos trovero-soneros en Corona, en el centro, y María Teresa Vera en occidente), sino además en fiestas familiares y populares muy arraigadas (crisol de nutrientes y fuentes a través de tradiciones familiares urbano-rurales), y manifestaciones muy poco estudiadas por aquel entonces (y aún hoy, salvo en mis trabajos) que han tenido un rol crucial (desde el fondo oculto) en los procesos más trascendentes de la música y cultura cubanas con múltiples nexos.

Aquel ambiente, ¿lo atraía, entonces, desde el punto de vista investigativo?

Todo ese sustrato sonero-trovero, festivo-popular, familias raigales, etc., fue "trabajando" indirectamente sobre mí, dejando las huellas de sus códigos, hasta que años después, más aún al regreso de mi estancia profesoral en la ENA, influyó para que, a partir de algún momento, me volcara de lleno en el estudio de buena parte de tales procesos, pero no en los más visibles, ni sólo en el entorno santiaguero, sino en lo profundo de los procesos músico-culturales cubanos.

18 Sé que en la construcción de su pensamiento también han sido esenciales las ciencias...

19 Por esa época incursioné en las ciencias básicas mediante disciplinas como análisis Matemático, Física Superior, Álgebra Superior y Boole, Estadística (convencional y no paramétrica), Teoría de las Probabilidades, Filosofía, etc., que estudié paralelamente en la misma Universidad de Oriente en cursos regulares y extracurriculares. Estas disciplinas, que de momento no convergían directamente en mi vida musical, tuvieron 
especial influencia en el desarrollo del pensamiento abstracto en mi mundo particular, aspecto que, de paso, pienso debiera tenerse mucho más en cuenta, equilibrada y adecuadamente, en la estimulación de la creación, interpretación y análisis musical en profesionales de la música y algunas otras ramas.

20 Antes de adentrarnos en los entretejidos orozquianos, algo medular en su pensamiento, hablemos más de su génesis científico-teorética.

21 Desde muy joven se me enterró la puntilla del acercamiento conceptual y teorético a la música, en términos generales y de la manera más insospechada. A la par de todas las experiencias musicales narradas, chocaba con los elementos analíticos de las escalas e instrumentos musicales que recibía del profesor Soro del Rey, destacado físico de la época, persona muy culta y de gran calado humano. Lo que él me sembró, como germen de inquietudes conceptuales, científicas y filosóficas (muchas asociadas a la música) fue para toda la vida y esto se potenció mediante mi quehacer musical.

¿Cómo ha sentido y experimentado la dinámica entre lo científico y lo musical?

Paralela y gradualmente. La inclinación conceptual y teorética se inscribe en el mismo devenir intrínseco de mi vida y nada tuvo que ver -como tiende a observarse en no pocos casos de la carrera musicológica- con alejamientos o dificultades con la música misma, sino exactamente lo contrario.

Mi formación aleatoria e irregular decidió en mis pasos posteriores. Me empujó igualmente a un frenesí autoformativo que abarcó la armonía y el contrapunto, la orquestación, el análisis apoyado en aquellas sensibles vivencias y, sobre todo, en un bagaje bibliográfico, casi excepcional a mi edad (entre quince y dieciocho), no sólo motivado por una intensa vocación y aptitud, sino también en la existencia de fuentes y amigos bibliógrafos -en especial, el increíble Rolando Ramos, de la Universidad- que me tenía al tanto de lo último en libros, revistas especializadas y folletos referenciales muy importantes (excepcionales, diría). Tuve acceso temprano a una bibliografía y a fuentes extraordinariamente excepcionales (inglesas, estadounidenses, francesas, francobelgas, y similares) de las más avanzadas, al extremo que ese nivel de información y autoformación asombró a una gente tan acuciosa y crítica como el compositor Carlos Fariñas, cuando me recibió por ves primera en el Departamento de Música que él dirigía en la Biblioteca Nacional. Allí le mostré algunas fuentes y el libro-biblia de Claude Samuel sobre las vanguardias musicales (entonces cabecera para mí), de donde incluso él extrajo, posteriormente, una separata para una importante actividad pública con la música del célebre greco-francés Xenaquis (mientras yo estaba en ese momento con mis alumnos de la escuela en Isla de la Juventud).

Me imagino que, con el bagaje informativo-conceptual acumulado y las experiencias vivenciadas por usted hasta ese momento, pertenecer al claustro de profesores de la ENA haya sido una ocasión fenomenal para trasmitir, validar y reinterpretarlo todo.

Aquello fue la apoteosis, pues con un no despreciable bagaje pero sin ninguna experiencia docente intensa (aunque sí audacia a veces "irreverente"), acometí aquel empeño que comenzó por la Acústica Musical pero en poco tiempo se extendió -en la Biblioteca o en mi "albergue-Monasterio", le decían- a seminarios extracurriculares sobre Música Vanguardista Contemporánea, Teoría de la Armonía, Procedimientos Analíticos Avanzados, amén de audiciones especiales de obras y/o compositores poco manejados de todos los tiempos (Palestrina, Monteverdi, Victoria, Gluck, Schöenberg, Webern, Messiaen, Boulez, Xenaquis, Henry,etc.). Confieso que, con la falta de 
experiencia, muchas de mis clases iniciales resultaron muy áridas para el alumnado. Con mucho esfuerzo y dedicación logré ir adecuando los contenidos, los procedimientos, los niveles y luego vino la plenitud en los posteriores seminarios, pero en realidad costó bastante. Nadie se explicaba, a decir verdad, ni yo mismo, de dónde sacaba para impartir aquellos "cosones" (de contenido y enfoque), que resultaban complicados aún para músicos habituales de mayor experiencia. Por ejemplo, en la época en que estudiaban en Polinia José Loyola y Roberto Valera (amigos y destacados colegas), yo proyectaba en seminarios un estudio comparativo entre el legado de I. Xenaquis y la Escuela Polaca de Composición (Penderecki, Lutoswaski, y otros), las acciones vanguardistas del círculo ecléctico de París (con Messiaen, Boulez/Henry, Maderna, Xenaquis), del grupo italiano (Nono-Maderna, Berio) del grupo de Colonia (Eimer, Stockhausen,etc.), y muchas otras.

¿Quiénes estaban entre sus alumnos?

Fueron alumnos míos los músicos Jorge Hernández (viola del Cuarteto Habana), Darío Morgan (posterior corno de la sinfónica), Tomás Fortín (que más tarde trabajó como primer director sistemático, con Jorge Luis Prats, durante un tiempo, y luego prematura y lamentablemente fallecido), Alejandro Ferreira (violín de agrupaciones de cámara), Pedro García (oboísta del cuarteto de maderas), Pedro Luis Ferrer (compositor-trovador y guitarrista), el destacado jazzista Emiliano Salvador, Olavo Alén y Jesús Gómez Cairo (inclinados a los estudios teoréticos y hoy directores de centros investigativos), Antonio Rodríguez (pedagogo guitarrista), Jorge Campos -Fumanchú(flautista-guía de posteriores agrupaciones populares importantes como el Maguaré), Jorge Fiallo 8entonces guitarrista y luego crítico-promotor), Luis Bayard (flautista clásico(, Jesús Rencurrel (clarinetista), Norma...la de dirección coral, Jesús Avilés (veterano y destacado oboísta de la Sinfónica) y muchos otros importantes músicos cuyos nombres se me escapan.

9 A partir de un momento dado, establecí también una especial relación con la incipiente y aportativa Charanga de la ENA, donde lideraban Adalberto Álvarez, el pianista y arreglista Andrés Alén, José Luis Cortés -el Tosco-, Joaquín Betancourt y varios más. Aquella Charanga no bien valorada entonces, y menos después, mucho aportó y adelantó (underground) al desarrollo de la música cubana de los años 70 a los 90 . Otros alumnos indirectos procedían de mis seminarios abiertos de Música Contemporánea, y las audiciones especiales de obras muy poco conocidas de todas las épocas y de la contemporaneidad. Entre ellos María Felicia Pérez (directora del Coro Exaudi), la cantora-directora coral Marta Padrón, el mismo Andrés Alén, muy activo en la discusión de los materiales (de las vanguardias) y otros. Y entre aquellos que, lamentablemente, sólo alcanzaron el corto y árido período de arranque (pienso no agradable), se encontraban el que luego fue notable compositor Juan Piñera, o la destacada pedagoga del piano Danae Ulacia.

Desde un punto de vista convencional, ¿podría decirse que usted fue alumno de Argeliers León?

La nuestra fue una relación superespecial. Cualquier intercambio y crítica mutuos con Argeliers devenía experiencia y enseñanza de un modo u otro. Pero de ahí a meterme en la bolsa común del resto de los jóvenes de la época (que también eran alumnos míos y en disciplinas intensas e inéditas en la Isla), hay un larguísimo trecho. Argeliers León, patriarca indiscutible de lo que hasta ese entonces era la etnología y el estudio folclorístico-musical (y luego de todo el panorama musicológico cubano) no tardó en hacer gran empatía y amistad conmigo. Me consideró y trató desde siempre como una 
suerte de profesional joven con el cual se daba un amplio campo de intercambio y discusión sistemáticas, lo cual incluía análisis conjunto de problemáticas fuertes, críticas y hasta chanzas ácidas mutuas (como se refleja en la espectacular dedicatoria que me hiciera de su clásico Del canto y el tiempo). En pocas palabras, fui un colega joven para la discusión y el intercambio, y fuimos muy buenos amigos.

Creo que se ha minimizado y hasta tergiversado mi papel de época, porque quizás a algunos les conviene la imagen "igualitarista" a ultranza (de "todos somos lo mismo"). De ser así, Argeliers no me hubiese invitado en 1979 -cuando había concluido aquel periodo de la ENA y oscilaba entre Santiago y La Habana- como miembro del histórico primer Jurado Casa de Musicología (donde por cierto confrontamos algunos roces en los análisis valorativos de las obras), ni yo hubiese sido invitado (también en el 79) como asesor especial para la música y la musicología en proyectos especiales del PNUD con sede regional en Bogotá.

33 Algo parecido podría narrar de la experiencia con Federico Smith, una de las personalidades más "raras", mental y musicalmente excepcionales que han pasado por nuestro contexto. Con un bagaje espectacular, desde las disciplinas musicales más tradicionales, pasando por un increíble dominio de la lectura al piano a primera vista, hasta muy sofisticados análisis que incluían las más complejas y abstractas matemáticas. Si excepcional era la personalidad de Smith, en el mismo grado era difícil su comunicación pedagógica (salvo cuando se tenía un background), ya que él asumía que todo era evidente y sólo iba a explicar "detalles". Dada mi propia formación multifacética aleatoria, no me era difícil conectar con cualquiera de los tópicos de un amplísimo campo dentro de la música, las matemáticas y las ciencias en general. Esas características propiciaron, igualmente, una muy efectiva comunicación con Smith, y sucedía con él (en este caso desde las matemáticas y la música) algo parecido a lo de Argeliers desde la etnografía y la musicología, en cuanto a condición de intercambio permanente y abierto. Smith fue una mentalidad excepcional que influyó en muchas personas y acciones. Creo que ha sido penosa la forma distanciada y fría en que se ha tratado su personalidad y se le ha olvidado hasta hoy.

¿Podría decirse que, de cierta manera, los estudios realizados por usted sobre la música cubana y sus procesos dan continuidad a la línea comenzada por Argeliers?

No lo diría exactamente así. Como es lógico, partí de insoslayables fuentes, como las etnoculturales, pero esto no se concentra sólo ahí. Lo fundamental es qué se hace con ésas y otras fuentes. Cómo ésta conecta con los datos establecidos y con el trabajo de campo reconstructivo, cómo se revela la dinámica entre subsistencia cotidiana y gran economía respecto a familias cultivadoras de tradiciones musicales (lo incidente y lo paralelo), cómo interaccionan lo rural y lo citadino, qué conexiones se establecen entre músicas ocultas (desconocidas o poco conocidas) y entre éstas con la música de festejos rural-urbanos y el dancismo de salón, la configuración de tipos genéricos, las conexiones abiertas, incluso con la composición individual.

36 Aplicando un estudio cruzado de procesos de esta índole, cobre mucha más potencialidad el uso de las fuentes clásicas, desde las etnoculturales de Fernando Ortiz y Lydia Cabrera, la fuente de los crítico y cronistas musicales del XIX, los resultados de Grenet, en uno de los estudios iniciales importantes de la música popular, el insoslayable panorama histórico-musical clásico de Carpentier, las contribuciones histórico-críticas de Ardévol y Edgardo Martín en la composición individual concertante, el acucioso estudio del dancismo del XIX de varias fuentes 8y en años 
después de Galán), entre otros nutrientes importantes y, desde luego, el fundamental y penetrante legado de Argeliers, al que se suma el valioso aporte historiográficofolclorístico y etnológico de Teté Linares.

¿Podría hablarnos del trabajo de promoción desplegado a lo largo de su carrera?

Entre 1970 y 1071 -todavía desde la ENA y poco antes de mi continua y fuerte oscilación entre Santiago y La Habana- había comenzado un trabajo promocional conjunto para alumnos y diversos públicos (aspectos de la contemporaneidad y algunas técnicas creativas) con el entonces joven e importante compositor Sergio Fernández Barroso. Una de las acciones de mayor relevancia ocurrió con un ciclo acerca de la trascendencia de los Beatles y su nexo con las fuentes musicales del Tercer Mundo, que se hizo en la capital y luego se trasladó a varias locaciones del país 8todo ello mucho antes de las importantes intervenciones que hiciera similarmente Leo por radio progreso). Esto interesó mucho al público, a pesar de que todavía prevalecían las erróneas medidas segregatorias y prohibitivas en nuestros medios hacia este célebre cuarteto que conmovió el rock-pop de los 60.

La prensa y los denominados promotores de nuestro ámbito han minimizado u ocultado este importantísimo periplo beatleano, y todavía hoy algún que otro promotor posterior de los Beatles lo ha obviado y hasta eliminado olímpicamente de sus historia y presentaciones (no sé exactamente por qué, pero el síndrome "plancha a Orozco" siempre sale cabrón en cualquier cosa, sea una clase o acción histórica, un ensayo, una nota o lo que fuese), pero ahí está, incluso documentado en programas y giras. En aquellas "acciones Beatles" no tardó en incorporarse de oyente Basilio Repilado, hijo menor de Compay Segundo, intenso beatleano y, por entonces, todavía no muy concientizado con los códigos de la música cubana tradicional que emanaba del padre. Posteriormente, Compay devino una de las fuentes musicales populares fundamentales en mi trabajo musicológico, también en el doctorado (82-87), y resultó centro de algunas de mis acciones promocionales. Por ejemplo, la que llevé a cabo para el evento mundial de 1989 en el Smithsonian Institute de Washington, un proyecto posterior víctima del síndrome "plancha a Orozco" en nuestro ámbito.

Durante los tempranos 70, luego de mi acción profesoral en la ENA, Leo volvió por Santiago y concebimos una acción bastante inusual y algo irreverente, pero muy efectiva. Por conveniencia promocional, decidimos efectuar un concierto de él con Sonatas de Scarlatti, por él transcritas, en una sala muy "sorda" de Santiago, y las dudas sobre la sala hacían tambalear todo. Luego de invertir los asientos y el escenario del local, buscando mejora sonoridad, se nos ocurrió la aventura de instalar a la guitarra un magneto eléctrico que utilizaba un superocurrente amigo común (Mondéjar) que hacía vida de clubes nocturnos y decía "Busco aires que dejen pesos". He ahí cómo se produce un acontecimiento mundial en Macondo: el asalto a Scarlatti por el magneto de Mondéjar mediante el guitarrismo de Leo, con un resultado mágico para aquel público que desbordaba espontáneamente el pequeño e inadecuado local.

Otro de los sedimentos más significativos de mi trabajo de años ha sido el vínculo humano, sociomusical y participativo con un número importante de familias que practican tradiciones de arraigo centenario de nutrientes africanos, hispanos, afrocaribeños, también de la vertiente de sones, de disímiles cantares o manifestaciones que representan segmentos importantes de la música, cultura e historia cubanas y hasta nexos tempranos poco conocidos con la cultura afroamericana, surestadounidense y caribeña. 

sobre mi faceta de promotor, es importante apuntar que, como consecuencia de aquellas investigaciones de campo, se me pidió organizar, para julio del año 88, un evento donde se reflejaran de algún modo las incidencias músico-culturales descritas. El evento costó sangre y hiel, pero resultó inusitado hasta para los que no creían. Se presentaron de diez a doce familias centenarias, de diversas zonas intrincadas y a la vez muy representativas de los procesos locales en conexión con el devenir nacional. Fueron apreciados por el público en una instalación abierta de Santiago, donde desplegaban los valores de su modo de vida y expresión musical, e incluso interactuado con grandes figuras como Omara Portuondo, Pablo Milanés (que mucho contribuyó), Sara, Pancho Amat (muy creativo como siempre), el pianista Frank Fernández (al que pedí colaboración en una realización escénica grande), incluso algunos músicos sinfónicos, y muchos otros. Este evento excepcional casi diez años antes de la "mundialidad" de algunos de los participantes (Omara, Eliades y el Compay), fue de nuevo pasado por el síndrome "plancha a Orozco y su accionar", por la paupérrima difusión...

Compay Segundo desde un tiempo antes ya se presentaba con Eliades Ochoa y el Cuarteto Patria. Durante una sesión especial matutina, Pablo, primero, se asombró de encontrarlo allí y luego estuco en la descarga y hasta cantó con ellos un rato (yo también hice segundo y rasgué un poco la guitarra). Según recuerdo, luego de este evento ocurrieron los proyectos entre Pablo y Compay (cercano a sus producciones disqueras en la serie Años y a las giras que hizo él en España, en etapas subsiguientes). Con posterioridad, el Ministerio y el incipiente Instituto de la Música (sobre todo en la 
persona de Alicia Perea) me solicitaron asesoramiento en la preparación de lo que sería la muestra cubana en el Festival Mundial de Arte Tradicionales del Smithsonian Institute de Washington, en junio-julio del 89. Para ello seleccioné a Compay con Eliades y el cuarteto, a la familia Valera-Miranda, al Changüí de Guantánamo y luego se sumó el Afrocuba de Matanzas. La denominada "preparación" consistía en un remontaje cuidadoso (estilísticamente hablando) de repertorios antológicos de la tradición cubana, sobre todo de las piezas populares significativas del Compay, desde los 40 (partiendo de las grabaciones de mi archivo), a veces yo también tocaba, siempre había un gran intercambio y chanzas agudas (todavía no hay "bonitura", decía Compay en una u otra sesión). Aquí se incluía su Chan Chan, que para entonces acababa de concebir (parafraseando tumbaos y añejos elementos de estilo), y no se olvide que estamos hablando del período 88-89. La muestra cubana en Washington resultó un éxito explosivo, así se reflejó en la prensa americana y se notificó a Cuba por los funcionarios del Smithsonian, quienes lo calificaron de muy relevante y "nunca visto en Estados Unidos", al tiempo que me expedían un Diploma-Distinción, como "contribución excepcional a la cultura mundial", dice así, haciendo énfasis en mi trabajo musicológico de preparación general unido a la descripción musicológica de la muestra para especialistas y para el público en Washington 8dirigí esto por teléfono ya que no obtuve visa -un "plancha a Orozco" diplomático- lo cual no impidió aquellos extraordinarios resultados). Pero en nuestro ámbito no sucedió nada, se dejó pasar la coyuntura de intentar un registro especial, aunque fuese sólo como memoria histórica, y ni eso...

Siguieron unas giras caribeñas con Compay y el Cuarteto más o menos exitosas, hasta que de nuevo el Instituto de la Música me pidió otra recomposición de muestra para un célebre evento en Sevilla, en 1994 y 95 (donde había coordinadores de ambas partes a quienes indiqué cómo contactar y qué hacer con el Compay). Ocurrió allí lo mismo y enseguida vinieron los primeros contactos de las disqueras canarias, acto seguido de Madrid y Francia. Éstos fueron los pies forzados para los posteriores de Ry Cooder y Nick Gold. Lo demás ya es historia repetida y supermanida: que si el Buena Vista hizo o no, que si descubrió o no que si el no plus ultra... Las antropofagias de las transnacionales son inevitables en el mundo globalizado, pero lo que sí no puede ocurrir es que usted no garantice su propia memoria histórica. No es asunto de blandir espada contra Cooder o Gold o Wenders, aunque de ingenuos no tienen un pelo (e incluso no se resalta suficiente la coordinación y dirección musical del cubano Juan de Marcos), pero el meollo es hacer uno lo suyo, no de querer competir sin recursos con imperios económicamente dominantes, pero hacer lo suyo y, de paso, sin griticos, también evitar (con los hechos y acciones) que le hable a uno de presuntos descubrimientos.

Claro, el bienestar económico de los artistas beneficiados es indiscutible y nadie lo condena, sólo basta poner un poquito en su lugar las cosas, y tampoco ser tan genuflexos o acríticos como se ven algunos funcionarios y una parte de nuestra prensa cada vez que mencionan a San Buena Vista, al fulanito o menganito del Buena Vista, etc., (por marketing se entiende, siempre y cuando no te lo creas tanto...), como si la calidad de Omara, Eliades, Compay o Ibrahim, o de los auténticos músicos cubanos, se debiera a eso. Sí le deben, claro, una mundialización masiva trasnacional, obedeciendo a fenómenos promocionales globales de hoy que deben quedar definitivamente claros, pero eso es harina de otro costal, no confundamos, señores. Los demagogos no somos los que hablamos con profundo conocimiento de causa y moral de entrega absoluta en 
años, sino esa pléyade de funcionarios y gestores que no creen en nada si no suena de afuera y, luego, enseguida blanden deditos queriendo dar lecciones... cubano y caribeño con diversas especies; también admitía, intuitivamente, su reflejo sicocreativo, su presencia en un sector específico de música concertante y en la poesía de Guillén, aunque no vio la especificidad y relativa autonomía de varios tipos genéricos concretos de sones (mucho menos los por mí denominados parasones y protosones), ni tampoco la autonomía de las especies caribeñas bajo condicionantes de procesos histórico-culturales bien específicos. Mi caracterización del "modo son" resume rasgos de código-macroestilo no circunscritos a uno u otro tipo de son, pero sí vinculados al proceso músico-cultural de los sones, a las marcas que se desprenden de tales procesos y que, por otro lado, se interceptan con aconteceres histórico-culturales y sicoculturales del ámbito cubano (en sus nexos), por lo que hurga igualmente en la subjetividad de creadores y receptores, y deja sus señales en una u otra manifestación sin detrimento de lo específico. También Leo Brouwer habla de "lo son" con algún punto de contacto respecto al sentido de Argeliers, y de otro lado se acerca a mi categorización, haciendo énfasis en las posibilidades abiertas creativas y del pensamiento, sin precisar detalles, y además, hace "correctivos" a los investigadores, lo que, por supuesto, y muy obviamente, no es extensible a cualquiera.

Muchos asumen por dada la existencia de una escuela musicológica cubana, ¿qué usted cree al respecto? 

hay dudas de que los logros fundamentales de la musicología cubana radican en la organización de su sistema de instituciones favorecido por el sistema social, la capacidad coordinativa para impulsar determinados proyectos de utilidad musicológica o sociocultural, la recopilación de materiales y muestras musicales para el desarrollo de diferentes investigaciones, la motivación permanente para la formación de nuevos musicólogos jóvenes que van cubriendo no pocas áreas de interés, la diversificación de temas y áreas de trabajo musicológico y la conformación de un relativo cuerpo teórico (o conceptual) para abordar ciertos problemas de no poca utilidad para los trabajos de los últimos años. no pocos casos. La obra formadora e integradora de Argeliers León desempeño un papel crucial y medular en la definición de un status básico de la musicología cubana, y a esto se unió la concreción de trabajos específicos de algunos jóvenes que estábamos al bate entonces, si bien no el summum, al menos con determinada proyección como para suscitar cierto interés.

Una cosa es esa realidad con determinado sedimento y otra muy diferente es la suerte de congelamiento del pensamiento musicológico cubano de los últimos tiempos, esto es, el poco contacto con el estado de la musicología mundial, no para repetir sus no pocas inconsecuencias sino para ubicarse y poder ejercer el monitoreo. Asimismo, el desconocimiento respecto a nuestros avances científicos (ya en la física o en la estructura y movimiento del universo, la dinámica del orden y el caos, el sentido revalorizado de la subjetividad humana, entre otros), los cuales tienen una muy sensible repercusión en diversas ramas del saber, en la filosofía y, desde luego, en la propia musicología, además de una aferrarse a esquemas analíticos y epistemológicos ya caducos o superados, de los cuales suele no tenerse ni la menor idea en nuestro ámbito... Es imprescindible, insisto, estar al tanto de lo que sucede, pero sobre todo para contracriticar $y$, en general, insertarse eficazmente en un panorama mundial convulso y duro, y a esto se añade el no poco anquilosamiento en el estudio y enfoque de la propia música cubana, frecuentemente apegada a lo establecido por años.

Para colmo, en ocasiones tampoco tienen en cuenta algunos importantes estudios socioculturales y de procesos cambiantes de identidad, de autores nuestros que según el caso pudieran ser útiles para contribuir a la profundización de aconteceres músicoculturales cubanos. No pocas veces se está al margen de procesos cruciales y concepciones culturales de la actualidad o de polémicos e importantes trabajos mundiales e incluso latinos (Maturana), una parte de los cuales están a la mano, hasta en español (por ejemplo, los culturológicos publicados por Desiderio Navarro en su valiosísima Criterios) para que después no vayan nuevamente a "descubrir mediterráneos" y a exaltar (como consuelo) determinadas opiniones positivas de algunos amigos acerca de las bondades o logros de nuestra organización institucional musicológica en comparación con la de otros, etc.

61 Sin embargo, podemos encontrarnos con la moda de utilizar a toda costa métodos traídos de afuera. 
62 Ese riesgo existe, pero depende del modo como se afrontan tales realidades, por lo que nunca podrá ser otro pretexto para eludir el meollo de lo que he venido exponiendo, esto es: la musicología cubana de nuestros días, por lo menos buena parte del mainstream, muestra sorprendente e intensa desactualización con el estado del conocimiento científico y en aspectos y procedimientos claves respecto a la propia musicología mundial. No quiere decir, insisto, que lo de afuera sea intocable ni modelo per se, bastantes incongruencias mantienen en enfoques y concepciones, por ejemplo, el no percatarse (en occidente) de la potencialidad del aporte afrocaribeñoamericano a la cultura mundial y de las consecuencias que eso tiene incluso en el proceder analítico. Es obvio que no se trata de correr tras los enfoques y trabajos de moda y mucho menos el aceptar todo cuanto salga, pero sí hay una obligación de conocer muy qué circula. No descubrir así "aguas calientes" y, por otro lado, actuar con todo el peso crítico y autocrítico.

Profe, en ocasiones escuchamos que usted escribe de manera barroca, se enfatiza en los recargado de su estilo, no así en su profundidad...

El lema de que yo escribo denso y complicado es otro subterfugio. Pueden ocurrir cosas, sobre todo en trabajos de cierta índole y en específicas condicionantes, aunque no se olvide que la teoría cuántica y la mecánica relativista, el principio de incertidumbre, los agujeros negros supermasivos, la teoría del caos y las redes y la percolación, e incluso materias musicales muy significativas como la trama de los barrocos, el dilema de las vanguardias y neovanguardias en la posmodernidad o el cruzamiento de procedimientos analíticos muy potentes, no son cosas precisamente ligeras ni "fresquitas", hay que meterles el pecho desde cualquier rama, a lo que dé, y en nuestro ámbito se ha ido perdiendo esa perspectiva. No me comparo, por supuesto, con los gigantes que han venido formulando esos conocimientos. Lo que quiero decir es que no se esgriman a los "cosones" actuales de la ciencia, la musicología, culturología o el mundo globalizado con sus "tenazonas" que, de paso, no son para correo ni dar griticos, señoras y señores, sino para saber torear e insertarse inteligentemente y con provecho para lo de uno como cultura raigal (siempre en transformación), y como individuo.

Con independencia de todos los avatares y fuertes limitantes (sobre todo las innecesarias) que uno ha debido librar y que más de una vez pueden atentar contra una adecuada concentración y tiempo para limpiar mejor uno $\mathrm{u}$ otro texto (cosa que ha ocurrido), esto no pasa de otro "toreao" o de una evasión metonímica descomunal respecto al punto nuclear real. Por ello, sólo me restaría sonreír con mucha piedad y pedirles a tales personas, en todo caso, que aprendan musicología, filosofía, ciencia e incluso música al duro (sin ir más lejos, ¿cuántos de nuestros musicólogos manejan profundamente el barroco -o los barrocos-, el clasicismo, la contemporaneidad o la misma música cubana más allá de lo establecido, o que no sea repitiendo o refriendo la martingala consabida hasta los 60 y 70?). Sólo después de esto veremos qué es escribir y redactar (no precisamente el simulacro y la metonimización de la realidad).

Tiene usted una especie de reprise de aquel Monasterio de la ENA en su Taller Musicológico de la Contemporaneidad que hace en el Teatro "Amadeo Roldán".

Da mucho trabajo mantenerlo porque se combinan mis problemas de salud con otros imponderables que me limitan muy de cerca. Ahí sembramos una semilla de estudio, formación y autonomía analítica (con materiales y procedimientos muy actualizados y controversiales que, obviamente, se requiere debatir y sedimentar). Para algunos que con este taller ponen el grito en el cielo y hablan de "dosificación" y de "tener mucho 
cuidado", les digo, entre otras cosas, que en la pedagogía de avanzada la dosis no consiste en dejar obligadamente para después, sino en la manera en que se va por el camino y cómo se establecen entretejido de relaciones y proyecciones (aunque claro no es "coser y cantar", pero tampoco la diablística actitud del "corte y costura" musicológico -todo "cuadraíto"). Así trabajo con algunos de los mejores prospectos jóvenes y otros profesores muy sensibilizados e inteligentes, y ojalá que eso pueda seguir delante de uno u otro modo. En cuanto a la perspectiva, ya no sólo con los jóvenes que se forman, sino además con las instituciones rectoras profesionales y docentes, diría que la veo en condiciones difíciles, porque hay mucha reticencia y prejuicio en el personal musicológico más establecido $8^{\mathrm{a}}$ veces de manera velada), amén de los ya conocidos "modelitos"; aunque siempre hay también gente importante y valiosa, incluso algunos funcionarios que comprenden y apoyan.

Reconozco que, sobre todo a partir de cierta etapa, he tenido buena comprensión y apoyo personal (humano y de trabajo) de las máximas instancias del Ministerio y el Instituto de la Música, pero ¡ojo!, creo que si no se eliminan una serie de procedimientos excesivamente formales o burocráticos (más o menos "diabólicos") provenientes de sectores o individuos que los alimentan, resulta prácticamente inoperante o casi imposible avanzar, por mucha voluntad que tengan máximas instancias. A veces uno se siente minimizado e impotente ante cosas de esa índole y, en ocasiones, he dicho: No se puede hace musicología a nivel mundial ni se puede competir en el sentido profundo técnico-musicológico y cultural, desde una chancleta de palo o de tela (me refiero más a la chancleta mental que incluso a la material), y ahora añadiría, quizás sí es posible, de hecho eso mismo he llevado a cabo a lo largo de incontables años (aunque con las duras huellas de esa desventaja y la marca del desgaste a veces innecesario). Pero podría añadirse: la musicología mundial desde nuestra perspectiva (cuando se despeje mejor el camino de las incongruencias e incompatibilidades), y también con chancletas de cualquier tipo, si no queda otro remedio, pero coño, compadre, aunque sea con un parche o una tira de goma delante para el precario sostén de los deditos con que se dan los pasos... O, jatención!, por lo menos con la erradicación sustancial de las chancletas mentales... ${ }^{1}$

\section{NOTAS}

1. Texto publicado una primera vez en la revista La Gaceta de Cuba, julio-agosto, № 4, UNEAC. Ciudad de la Habana, Cuba, 2004, pp. 24-29. 


\section{RESÚMENES}

Todo encuentro con el musicólogo Danilo Orozco (Santiago de Cuba, 1944-2013) correo el peligro de convertirse en un interminable diálogo, no sólo con la historia de la música y la musicología, sino con una corriente de pensamiento que se mueve entre interrogantes de muy diversa índole. Por una parte, su extensa e intensa carrera (experiencia docente abierta de treintaiséis años), colaborador de prestigiosas universidades e instituciones de todo el mundo como Smithsonian Institute de Washington, Universidad de California (Tribunal a distancia), Universidad Salamanca, Fundación Sojo de Caracas, Conservatorio TChaikovsky de Moscú, Universidad de Chile, Universidad de Austin (LAMR), la BBC de Londres y el Who's who in Music. Por otra, su categoría de doctor Summa Cum Laude en Ciencias Musicológicas y Filosóficas por la Universidad "Humbolt" de Berlín, Profesor e Investigador Titular en Cuba; además sus trabajo teórico-prácticos en problemáticas medulares de la historia y el análisis musical, sus casi "incapturable" cuatro libros, e innumerables ensayos, toto eso matizado por su admirable y multifacético desbordamiento, el carácter polémico y controversial de sus planteamientos, los "entramados" conceptuales de una mente en movimiento perpetuo.

Le musicologue Danilo Orozco (Santiago de Cuba, 1944-2013) a réalisé une carrière longue et intense, avec une expérience d'enseignement de trente-six ans. Il a été collaborateur assidu des Universités et des institutions prestigieuses à travers le monde telles que le Smithsonian Institute of Washington, l'University of California, l'Universidad de Salamanca, la Fundación Sojo de Caracas, le Conservatoire Tchaïkovski de Moscou, l'Université du Chili, l'Université d'Austin (LAMR), la BBC de Londres et le Who's who de la musique. Par ailleurs, il a été nommé Docteur Summa Cum Laude en Sciences Musicologiques et Philosophiques de l'Université Humboldt de Berlin, Professeur et Chercheur Senior à Cuba. Ses travaux théorico-pratiques versant sur l'importance de l'histoire et de l'analyse musicale, ainsi que ses débordements admirables et multiformes, défient les cadres conceptuels et les catégorisations et montrent un esprit en perpétuel mouvement.

\section{ÍNDICE}

Mots-clés: Danilo Orozco, Santiago de Cuba, histoire de la musique, musicologie

Palabras claves: Danilo Orozco, Santiago de Cuba, historia de la música, musicología

\section{AUTOR}

\section{MIVIAM RUIZ PÉREZ}

Directora Ejecutiva de Educación Artística de la Secretaría de Cultura de la Ciudad de México, Doctora en Ciencias sobre Arte 